\title{
Quantifying and mapping embodied environmental requirements of urban building stocks
}

\author{
André Stephan ${ }^{\mathrm{a}, 1}$ and Aristide Athanassiadis ${ }^{\mathrm{a}, \mathrm{b}, \mathrm{c}}$ \\ aFaculty of Architecture, Building and Planning, The University of Melbourne, Victoria 3010, Australia \\ ${ }^{b}$ Aspirant du F.R.S.-FNRS - Research Fellow at the Belgian National Fund for Scientific Research, 5 Rue d'Egmont, Brussels \\ 1000, Belgium \\ 'Building, Architecture and Town Planning, Université Libre de Bruxelles (ULB), 50 Av.F.-D. Roosevelt, Brussels 1050, \\ Belgium
}

${ }^{1}$ Corresponding Author

ORCID: 0000-0001-9538-3830

Tel: +61383445929

$+61452502855$

e-mail: andre.stephan@unimelb.edu.au

\begin{abstract}
Cities and their building stocks result in huge environmental impacts which are critical to reduce. However, the majority of existing studies focus on operational requirements or on material stocks. To date, very few studies have quantified embodied environmental requirements of building stocks and spatialised them.

This study describes a bottom-up approach to spatially model building stocks and quantify their embodied environmental requirements. It uses a highly disaggregated approach where each building's geometry is modelled and used to derive a bill of quantities. Construction assemblies relevant to each building archetype (derived based on land-use, age and height) are defined using expert knowledge in construction. The initial and recurrent embodied energy, water and greenhouse gas emissions associated with each material within each assembly are calculated using a comprehensive hybrid analysis technique. This model is applied to all buildings of the City of Melbourne, Australia.

Results show that rebuilding the City of Melbourne's building stock today would require $904 \mathrm{kt}$ of materials $/ \mathrm{km}^{2}$ (total: $32725 \mathrm{kt}$ ), $10 \mathrm{PJ} / \mathrm{km}^{2}$ (total: $362 \mathrm{PJ}$ ), 17.7 Million $\mathrm{m}^{3}$ of embodied water $/ \mathrm{km}^{2}$ (total: 640.74 Million $\mathrm{m}^{3}$ ) and would emit $605 \mathrm{ktCO}_{2} \mathrm{e} / \mathrm{km}^{2}$ (total: $23530 \mathrm{ktCO}_{2} \mathrm{e}$ ).

This study demonstrates the breadth of the model outputs, including material stocks maps and breakdowns of life cycle embodied requirements by material, construction assembly, building and building typology at the city level. Using such model, city councils can better manage building stocks in terms of waste processing, urban mining and circular economy, as well as reducing embodied environmental requirements over time.
\end{abstract}

\section{Keywords}

Urban and building environmental models; material stock; bottom-up; Melbourne; energy; greenhouse gas emissions

\section{Introduction}

The built environment is an essential component of human society. While cities are the epicentre of human activity, they also have a huge impact on the environmental system of the Earth. It is estimated that around $56-78 \%$ of global final energy use occurs in urban areas [1], of which buildings represent a significant share, and are responsible for large amounts of greenhouse gas emissions [2]. The building sector is also one of the most material intensive [3] and is responsible for huge amounts of waste. For example, 25-30\% of all waste generated in the European Union originates from the building sector [4]. Globally, the building sector has the largest demand for materials, notably non-metallic minerals [5].With a forecasted population growth of 2.7 billion over 
the next decades, most of which expected to live in cities [6], it is essential to better understand the resource use of urban building stocks in order to provide actors and decision-makers with tools that can effectively help minimise direct and embodied energy, water and material use and reduce greenhouse gas emissions.

Different modelling approaches can be used to quantify environmental flows and stocks in cities and the built environment. Among these approaches urban metabolism characterises the city as a living organism that requires a range of inputs and outputs to sustain its operation and its inhabitants' needs [7-9]. While urban metabolism captures a broad range of environmental indicators, it is often seen as a "black box" that cannot identify the drivers behind these inputs and outputs [10]. Material flow analysis (MFA) is a technique used to quantify the inputs, outputs and stocks of materials in order to determine the material metabolism of a precinct [11, 12], cities $[13,14]$ or countries [15]. Multiple studies have estimated the material quantities of different urban stocks and these rely on either a bottomup, a top-down, or a demand-driven approach, as summarised in Tanikawa et al. [13]. However, even a bottom-up approach often relies on average material intensities per floor area (e.g. per square metre), failing to capture more detailed information about construction assemblies and their spatial organisation. Also, these material flow analyses do not consider the embodied environmental requirements associated with the production of these materials therefore offering only a single perspective of the resources that are needed to build and maintain a building stock.

Another field of research that specifically targets energy use in cities is urban building energy modelling [16]. This approach typically uses building archetypes and physical models to estimate operational energy requirements for each building (e.g. Howard et al. [17]) and has been facilitated by the increasing computation capacity of recent computers that can model an entire neighbourhood or city $[18,19]$. In a recent review on the energy modelling of district energy systems (including buildings), Allegrini et al. [20] revealed that very few existing tools include the embodied energy of buildings, and those that do, implement only basic calculations, failing to capture detailed material quantities or entire supply chains. Based on these observations, embodied environmental requirements seem to be overlooked in these approaches. The reason for omitting embodied requirements might be the belief that they represent only a small fraction of their operational counterpart, as indicated in many studies and reviews of life cycle assessment at the building scale (e.g. [21-26]). However, this reduced contribution can be explained by the reliance on the process analysis technique for the quantification of embodied requirements. This technique is known to underestimate embodied requirements due to its limited system boundaries [27-29]. At a whole building level, studies by Crawford [30], Crawford and Stephan [31] and Stephan and Stephan [32], found that process analysis can underestimate embodied energy by a factor of $\sim 4$ on average, compared to the more comprehensive input-output-based hybrid analysis [33]. For example, Stephan and Crawford [34] used input-output-based hybrid analysis and found that embodied water is more significant than operational and user-transport water requirements over 50 years, for a new building and its occupants in Melbourne, Australia. Moreover, recent studies on energy efficient buildings show that the contribution of embodied energy to the total is not only increasing because of the reduced operational energy use [35] but that after a certain insulation level, the embodied energy of the additional insulation becomes more significant than the energy savings it will provide during its lifetime (50 years in that case) [36]. Based on these findings, taking into account embodied environmental requirements in the built environment is therefore crucial as they represent a significant and hidden share of urban resource use [37]. These are often quantified using life cycle assessment.

A large number of studies have applied life cycle assessment (LCA) [38] to buildings, across many countries and regions, as demonstrated by a number of recent reviews in the field [25, 39-41]. However, the application of LCA to neighbourhoods or precincts is much less common. In their recent review on the topic, Lotteau et al. [42] have identified 14 studies that 
undertake a life cycle assessment at the neighbourhood level, of which only 9 actually model the entirety of the neighbourhood, across its surface area. These studies typically consider embodied (for building materials and construction), operational and transport requirements of buildings and their inhabitants and some also include requirements for infrastructure. However, the majority of these studies provide only aggregated embodied requirements results, such as the total energy or greenhouse gas intensity of the neighbourhood (e.g. Nichols and Kockelman [43]). Very few studies (e.g. Stephan et al. [44]) provide the embodied energy by material or assembly, enabling thus better decision-making for a number of stakeholders. Furthermore, the exponentially growing number of parameters at a larger scale limits these LCA studies to neighbourhoods. To date, the embodied requirements associated with material production and building construction at a city level have rarely been quantified with very few studies spatialising results (e.g. Pincetl et al. [45]). In light of the forecasted growth in urban population [6], it is critical to better understand the embodied requirements of the built environment in order to inform decisions regarding the construction and maintenance of the building stock, as well as urban mining [46] and urban planning and design.

To summarise, current environmental assessments at the city level tend to focus either on operational aspects, such as energy, water or material use, or on material stocks, omitting embodied environmental requirements. Furthermore, top-down techniques which do not provide a high spatial resolution are used in most studies. Even when bottom-up models are applied, these tend to rely on average intensities for estimating environmental requirements, typically average material intensities per floor area in building stocks models. These average intensities disregard the three dimensional geometry of each building. There is therefore a need for a bottom-up approach that models the city at a high spatial resolution and includes construction aspects, assemblies and materials. On the other side of the spectrum, studies that consider and measure embodied environmental requirements are often carried out at the building scale or at the neighbourhood scale at best. This research aims to address both of these gaps simultaneously which will allow a more comprehensive, disaggregated and realistic quantification of embodied requirements in cities.

\subsection{Aim and scope}

The aim of this paper is to propose a bottom-up approach to quantify and map embodied environmental requirements of urban building stocks. It uses the City of Melbourne, Australia as a case study to demonstrate the potential and relevance of the developed approach.

The life cycle stages taken into account comprise raw material extraction, material manufacture, processing and transport as well as the construction and maintenance of buildings. The end-of-life stage is not taken into account because of the significant uncertainties regarding the fate of a building many decades into the future. The proposed method quantifies the embodied primary energy, greenhouse gas emissions and water requirements of all building materials (including all inputs and/or outputs across the supporting supply chains). The building material stock is also quantified. While these indicators have been included in this study, more could be integrated into the model, as discussed in Section 4, depending on the needs of each stakeholder.

\subsection{Structure}

Section 2 first describes the proposed bottom-up approach including data requirements, quantification algorithms and mapping tools. Section 3 applies the developed approach to the City of Melbourne, Australia in order to illustrate its potential. Section 4 discusses the modelling approach and presents its limitations in light of the results of the case study. Section 5 concludes the paper.

\section{Designing a bottom-up approach to quantify and map embodied environmental requirements in cities}

Contrarily to top-down environmental modelling approaches, which often rely on aggregated data 
and operate at a large scale, bottom-up models use a disaggregated combinatory approach that relies on a range of different parameters and is scaled up or aggregated to represent the entire system [19]. Through this disaggregation, a bottom-up approach can provide a much higher resolution in the results since particular environmental effects can be traced back to a particular construction element or material [47]. Moreover, a bottom-up model provides a robust basis for future scenario modelling as even minor variables can be modified in order to examine and evaluate their impact on the entire system. However, bottom-up approaches often require a significantly larger amount of data and expert knowledge to realistically model individual components and parameters of a system.

This section describes the bottom-up approach used to quantify and spatialise the environmental requirements in cities, including the model, its data requirements, the algorithms used and how it can enable decision-making.

\subsection{Overall modelling approach}

This research uses the bottom-up model developed by Stephan [48] and presented in Stephan and Crawford [49] and Stephan and Crawford [34] to evaluate the life cycle embodied energy, greenhouse gas emissions, water use and material use of each building within a city. While the model used also quantifies operational and user-transport requirements (for residential buildings), these fall out of the scope of this paper and will not be covered here. The algorithms used to quantify material and embodied requirements are presented in Sections 2.3 and 2.4, respectively.

The model combines building materials into a range of different assemblies. For example, a door assembly contains timber panels, timber framing, a lintel (timber, steel or reinforced concrete), hinges, a lock, a handle and paint. This reveals the level of detail allowed by the model. These assemblies are attributed to different building types (office, apartment, house, retail, etc.), ages and heights (low/medium/high-rise), using the so-called 'archetypes' approach $[18,47]$. However, the main difference in this study resides in the estimation of the bill of material quantities.
Most existing studies that rely on the archetypal approach model operational energy use [18, 19, 47] and not embodied environmental or material requirements. These studies are often more concerned with the thermal characteristics of envelope elements, occupancy, efficiency of building systems and other operation-related parameters. Estimating the quantity of materials in a building is secondary. However, this is the focus of studies that attempt to model the building material stock $[11,13]$. The majority of such studies use so-called 'material intensity' factors for each archetype in a city. These factors provide an average material use per square metre of floor area, e.g. kg of timber per $\mathrm{m}^{2}$ of floor area, or per $\mathrm{m}^{3}$ of gross building volume [50,51], and can be broken down by element (e.g. kg of timber in doors per $\mathrm{m}^{2}$ of floor area). While a material intensity by floor area approach can provide a realistic estimate at the city or precinct level, it can significantly differ from reality at a smaller scale, notably for vertical assemblies. For example, the quantity of external walls for two buildings of $225 \mathrm{~m}^{2}$ of floor area would be the same when using this approach. However, considering that one building has a square plan of $15 \mathrm{~m} \times 15 \mathrm{~m}$ and the other a rectangular plan of $8 \mathrm{~m} \times \sim 28 \mathrm{~m}$, the resulting quantity of outer walls would be $20 \%$ higher for the second, considering all other parameters equal. The same logic can applied for material intensities per $\mathrm{m}^{3}$ but an additional source of uncertainty is introduced with building height. While this might not have significant impacts on aggregated results at the city level, it does offer an opportunity to capture building geometry and provide more accurate estimates when considering parts of the city, such as suburbs, neighbourhoods or streets.

This study derives actual bill of material and assemblies quantities for each building, using its basic geometrical characteristics in order to better approximate materials used and associated embodied environmental requirements. A detailed material composition allows more precise modelling. While this requires more information and is more sensitive to assumptions made, it allows setting up a model that can be progressively enriched in time, as more detailed data becomes available or when data is available for particular buildings. The study by Assefa and 
Ambler [52] on a case study building at the University of Calgary campus, Canada is an example of the level of detail that would be possible to introduce in the model for particular buildings.

In addition, the term environmental requirements is preferred to environmental 'impact' as this study quantifies input flows, i.e. energy and water, an output flow, i.e. greenhouse gas emissions, as well as the material stock. It does not perform the 'life cycle impact assessment' stage of a life cycle assessment and stops at the 'life cycle inventory stage' [38].

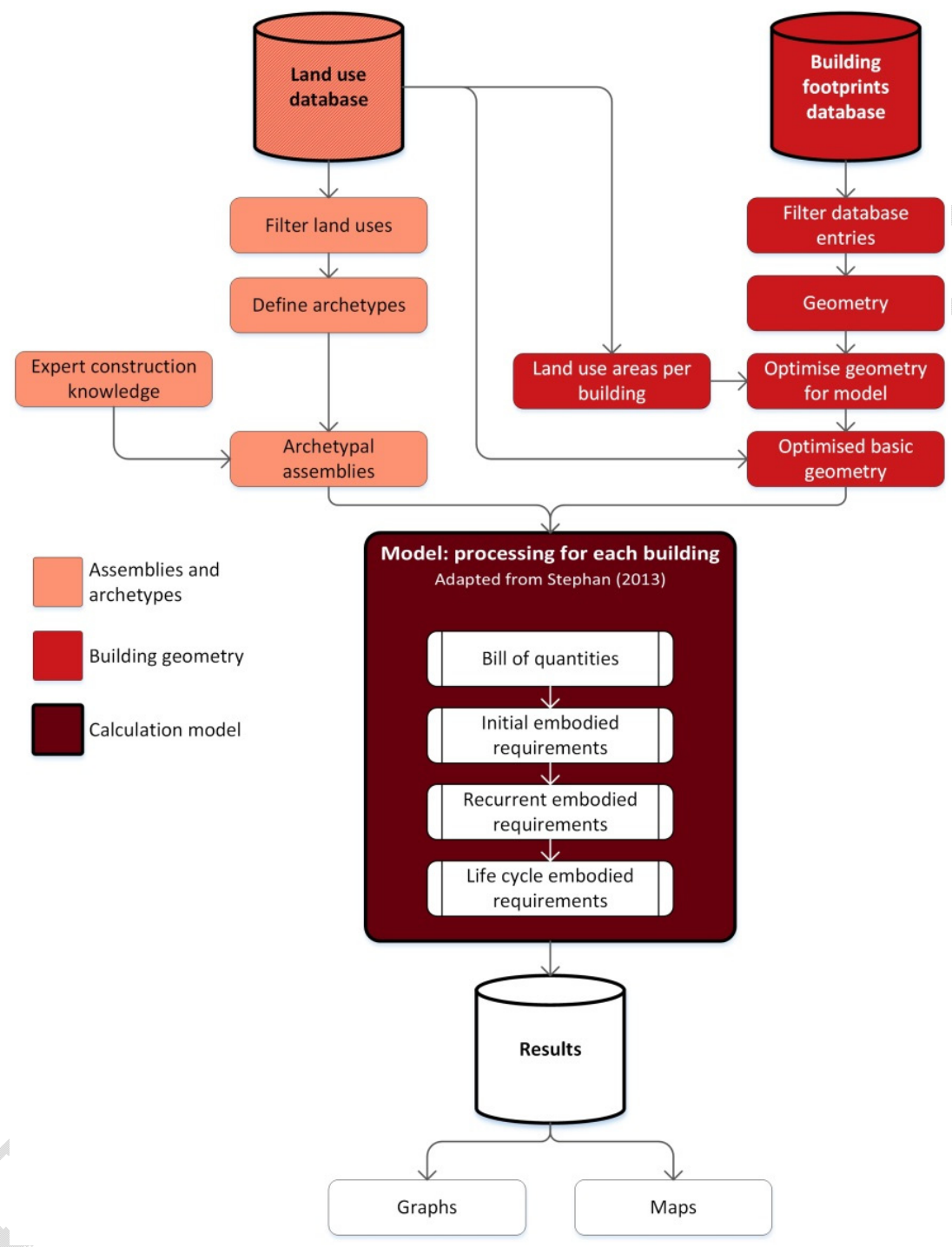

Figure 1: Overall modelling approach

Figure 1 presents the overall modelling approach used, its data requirements and the different steps involved. It will be referred to throughout Sections 2 and 3 . The process starts with two parallel streams of data processing: one focusing on assemblies and archetypes and the other on building geometry. The resulting archetype and assemblies definitions as well as basic geometrical variables are supplied to the model which estimates the bill of quantities for each building, calculates initial, recurrent and life cycle embodied requirements and generates a database of results.

\subsection{Data requirements}

As in most bottom-up approaches to model the built environment, a large amount of data is required. In this case, data requirements encompass land-use data per building, building footprints and geometry, a database of material embodied requirements and a database of assemblies definitions. The land-use and building 
footprints databases are becoming increasingly available in many cities with open data policy (see The Open Data Institute [53] for more information). Databases of embodied environmental requirements for construction materials are also becoming more extensive and cover different countries/regions (e.g. ICE [54], ecoinvent [55], and hybrid material databases [56]). Databases of construction assemblies are much less common and are generally compiled on a project basis and specified in each study. These require significant expert knowledge, notably in construction and architectural history.

The data intensiveness of the proposed model significantly increases uncertainty in the results because of different assumptions used in different datasets, encoding errors in third-party data and differences in system boundaries used in determining embodied environmental requirements. These factors can significantly affect the quality of the results. In case of missing data, realistic, informed and documented assumptions could be made. However, the highest level of transparency should be provided for others to understand the origins of such assumptions and to enable the reproducibility of the study. More importantly, it is only if a sufficient level of data is available, that assumptions can be used. Below a certain threshold, the lack of data simply prohibits the use of the model. The hierarchical significance of data starts with building floor area, building typologies, geometry and then embodied environmental coefficients for building materials. This is because even without the latter, a relatively reliable building stock model can still be established. Environmental requirements can be derived using generic databases in order to

Table 1: Description of the assemblies used in the model and the quantification of their quantities provide an order of magnitude at start and be gradually enriched with more specific life cycle inventory data. This improves the applicability of the method to different cities. The proposed model should be seen as the backbone over which higher quality data can be added as they become available rather than a definite fixed representation of a city's building stock. In addition, the enhancement of the results at a city scale without having to modify large amounts of data is only possible when using a highly disaggregated and bottom-up model such as the one described here.

\subsection{Quantifying material requirements}

The proposed material quantity estimation model adapts the approach developed by Stephan [48] for residential buildings to other building types. Each building is approximated by a rectangular shape that has the same area and perimeter as the real building. The dimensions of the rectangle are obtained by using an optimisation algorithm (see Section 1.1.). The width and depth of the building are combined with its height between stories (depending on building type), number of stories (from the land-use database), window to wall ratio (depending on building type), structural span (depending on building type) and roof slope (depending on building type) to provide the set of basic geometric variables used to derive the bill of quantities of 18 assembly types. These are listed in Table 1, along with their functional units and the equation/description of how they are derived. Note that the quantities of minor assemblies, such as wires, pipes and minor finishes are quantified using a typical intensity per $\mathrm{m}^{2}$ approach.

\begin{tabular}{lll}
\hline Assembly & $\begin{array}{l}\text { Functional } \\
\text { unit }\end{array}$ & Quantification Equation/Description \\
\hline $\begin{array}{l}\text { Concrete in } \\
\text { foundation }\end{array}$ & $\mathrm{m}^{3}$ & $\begin{array}{l}\text { The quantity of concrete in foundations is calculated based on the type of } \\
\text { foundation, i.e. raft, piles, continuous footings or individual footings. These } \\
\text { foundations are dimensioned dynamically based on the number of stories and } \\
\text { typical loads per building type, using structural equations. }\end{array}$ \\
$\begin{array}{l}\text { Steel in } \mathrm{t} \\
\text { foundation }\end{array}$ & $\begin{array}{l}\text { The amount of steel in foundations is derived from the amount of concrete } \\
\text { using a steel reinforcement coefficient in t of steel per } \mathrm{m}^{3} \text { of concrete, ranging } \\
\text { from } 0.07 \text { to } 0.13 \mathrm{t} / \mathrm{m}^{3} \text {. }\end{array}$
\end{tabular}




\begin{tabular}{lll}
\hline Assembly & $\begin{array}{l}\text { Functional } \\
\text { unit }\end{array}$ & Quantification Equation/Description \\
\hline Columns & $\mathrm{m}$ & $\begin{array}{l}\text { The length of columns in a building is calculated by imposing a regular } \\
\text { orthogonal mesh on the building plan, using a square pattern with a side equal } \\
\text { to the structural span defined per building type. The number of columns is then } \\
\text { multiplied by the height between stories. Columns are only present in buildings } \\
\text { that do not rely on bearing walls for their structure. }\end{array}$
\end{tabular}

Beams $\mathrm{m}$ The length of beams in a building is calculated by imposing a regular orthogonal mesh on the building plan, using a square pattern with a side equal to the structural span defined per building type. The length of beams is obtained by considering the minimum amount of beams to install based on a span along the width or the depth of the building. Beams are only present in buildings that do not rely on bearing walls for their structure.

$\begin{array}{ll}\begin{array}{l}\text { Ground } \\ \text { floor slab }\end{array} & \mathrm{m}^{2} \\ \text { Upper floor } & \mathrm{m}^{2} \\ \text { slab(s) } & \\ \text { Lift(s) } & \text { no } \\ \text { shaft(s) } & \\ \text { and } & \\ \text { staircases } & \end{array}$

$G F S_{b}=w_{b} \times d_{b}$

$U F S_{b}=\left(w_{b} \times d_{b}-A L S S_{b}\right) \times N S_{b}$

Outer walls $\mathrm{m}^{2}$

$A O W_{b}=\left(1-W F R_{b}\right) \times\left[2 \times W_{b}+\left(N F_{b}-2\right) \times d_{b}\right] \times h_{b} \times N S_{b}+\frac{\tan \left(R S_{b}\right) \times w_{b}^{2}}{2}$

Party walls are obtained using:

$$
A P W_{b}=\left(4-N F_{b}\right) \times d_{b} \times h_{b} \times N S_{b}
$$

Windows $\quad \mathrm{m}^{2}$

$$
A W_{b}=W F R_{b} \times\left[2 \times W_{b}+\left(N F_{b}-2\right) \times d_{b}\right] \times h_{b} \times N S_{b}
$$

Roof $\quad \mathrm{m}^{2}$

$$
A R_{b}=2 \times \frac{w_{b}}{\cos \left(R S_{b}\right)} \times d_{b}
$$

Internal $\quad \mathrm{m}^{2}$

walls

$N F_{b}<4: A I W_{b}=\left(2 \times w_{b}+d_{b}\right) \times h_{b} \times N S_{b}$

$$
N F_{b}=4: A I W_{b}=\left(3 \times w_{b}+2 \times d_{b}\right) \times h_{b} \times N S_{b}
$$

The area of internal walls is subsequently corrected for each building type based on typical floor layout plans.

Doors no

The number of doors is obtained by dividing the floor area by the average room size, depending on the building type, e.g. $15 \mathrm{~m}^{2}$ for residential buildings.

Flooring $\left(3 \mathrm{~m}^{2}\right.$ types)

Each building can have up to three different types of flooring. The total flooring area is equal to the usable floor area, obtained by multiplying the gross floor area by $0.9^{a}$. The percentage of each flooring type is determined according to the building type.

Pipes $\quad m$

The length of pipes is obtained by multiplying the gross floor area by an average intensity ${ }^{b}$. 


\begin{tabular}{lll}
\hline Assembly & $\begin{array}{l}\text { Functional } \\
\text { unit }\end{array}$ & Quantification Equation/Description \\
\hline Wires & $\mathrm{m}$ & $\begin{array}{l}\text { The length of wires is obtained by multiplying the gross floor area by an } \\
\text { average intensity }\end{array}$ \\
$\begin{array}{l}\text { Minor } \\
\text { finishes }\end{array}$ & $\mathrm{m}^{2}$ & $\begin{array}{l}\text { The minor finishes category regroups minor elements, such as cupboards, } \\
\text { closets and bathroom ceramics. Other finishes are expressed per } \mathrm{m}^{2} \text { of usable } \\
\text { floor area, based on the building type. }\end{array}$
\end{tabular}

Where (assembly quantities are indicated in bold):

$b=$

A building

$\mathbf{G F S}_{\boldsymbol{b}}=$ Ground floor slab area of building $b$ in $\mathrm{m}^{2}$;

$\mathrm{UFS}_{\mathrm{b}}=$ Upper floor slab(s) area of building $b$ in $\mathrm{m}^{2}$;

$w_{b}=$

Width of building $b$ in m;

$d_{b}=$ Depth of building $b$ in $\mathrm{m}$;

$N S_{b}=$ Number of storeys of building $b$;

$A L S S_{b}=$ Area of lift shafts and staircases for each floor of building $b$ in $\mathrm{m}^{2}$;

$A O W_{b}=$ Area of outer walls of building $b$ in $\mathrm{m}^{2}$ (excluding windows and including potential gables);

\section{$A P W_{b}=\quad$ Area of party walls of building $b$ in $\mathrm{m}^{2}$; \\ $W F R_{b}=\quad$ Windows to façade ratio of building $b$;}

$N F_{b}=\quad$ Number of façades of building $b$, i.e. 2,3 or 4 ;

$h_{b}=\quad$ Floor to ceiling height of building $b$ in $\mathrm{m}$;

$R S_{b}=$

Slope of the roof along the depth $d_{\mathrm{b}}$ of building $b$, in degrees;

$\begin{array}{ll}\boldsymbol{A} \boldsymbol{W}_{\boldsymbol{b}}= & \text { Window area of building } b \text { in } \mathrm{m}^{2} ; \\ \boldsymbol{A} \boldsymbol{R}_{\boldsymbol{b}}= & \text { Roof area of building } b \text { in } \mathrm{m}^{2} ;\end{array}$

and

$A I W_{b}=$ Internal walls' area of building $b$ in $\mathrm{m}^{2}$.

aBased on Fay [57]

bBased on Du Bellay et al. [58]

The bill of quantities estimations have been validated for residential buildings and result in a deviation of $\pm 10 \%$ at most from actual quantities, as shown in Stephan [48]. In addition, the estimations for non-residential buildings are based on typical floor layouts and are therefore expected to result in a realistic approximation. Note that building systems and infrastructure are not considered in this model. Potential deviations, uncertainty and omissions are discussed in Section 4.3.

\subsection{Quantifying requirements}

This study uses the process-based hybrid analysis approach developed by Treloar [33] to quantify the embodied energy and water requirements associated with building materials. Hybrid analysis is chosen as it is the most comprehensive life cycle inventory analysis technique to date [27, 28, 59], having the most extensive system boundaries. Embodied greenhouse gas emissions are derived from embodied energy figures using an average emissions intensity for the Australian industry of $60 \mathrm{kgCO}_{2} \mathrm{e} / \mathrm{GJ}$, as in $[49,60]$. Processbased hybrid analysis combines industrial process data for construction materials with top-down economic data representing transactions within the Australian economy and their environmental intensities. The combination of both figures ensures that the system boundaries are comprehensive for each material and that more reliable process data is used where possible. Capital investments across the economy are taken into account in the input-output models according to the method described in Lenzen and Treloar [61]. Each material coefficient therefore represents the total cradle-to-gate requirements needed for raw material extraction, material manufacture and processing. Equation (9) shows how the embodied energy coefficient of a material is calculated and is adapted from Crawford [30]. 


$$
E C_{m}=P E R_{m}+\left(T E R_{s}-\sum_{p=1}^{p} D E R_{p}\right) \times C_{m}
$$

Where:

$E C_{m}=\quad$ Hybrid energy coefficient of the basic material $m$ in $\mathrm{GJ} /$ functional unit;

$P E R_{m}=\quad$ Process energy requirement of material $\mathrm{m}$ in $\mathrm{GJ} /$ functional unit;

$T E R_{s}=\quad$ Total energy requirement of the input-output sector $s$, representing material $m$, in GJ/currency unit;

$D E R_{p}=\quad$ Direct energy requirement of the input-output sector $p$, representing the material production processes for which process data is available and covered by PERm, in GJ/currency unit; and

$C_{m}=\quad$ cost of the basic material $m$ in currency units.

Crawford [30] and Crawford and Stephan [31] have found that process-based hybrid analysis produces figures 1.98 and 2.28 times higher than relying on process data, respectively. However, process-based hybrid analysis does not take into consideration the indirect requirements that support the construction of the building, transportation to site and other aspects linked to the construction project itself, such as advertisement, insurance and others. The socalled 'input-output remainder' could be added to process-based hybrid analysis figures to obtain an input-output-based hybrid analysis quantification, which is systemically complete [29]. While this has already been undertaken in studies on new buildings and neighbourhoods, it becomes extremely complex when trying to apply it at the city scale, especially when used on older buildings.

It is important to note that the estimation of embodied requirements assumes that these are constant across time. The resulting initial embodied energy of a city therefore corresponds to the amount of energy spent on building materials, had the city been built from scratch today. There is therefore a significant amount of uncertainty in these figures as it is impossible to obtain annual process and input-output data from the year of construction of the oldest building in Melbourne to date. However, such intensities are very informative for new developing cities that are rapidly growing as they provide an order of magnitude of embodied requirements, something that has rarely been studied before.

In addition to initial embodied requirements, recurrent requirements associated with the replacement of building materials across time are taken into account in the model. It is critical to consider recurrent embodied requirements, not only because these are significant [62], but also because the replacement of materials is one of the main drivers of material flows exiting the urban system that could become either waste or secondary resources depending on the waste management strategies adopted [63]. Therefore this model can help provide opportunities for a circular economy and allows quality improvements to the building stock, notably in terms of energy efficiency [64]. Recurrent requirements are considered from the year of construction of each building until a selected time horizon, e.g. 2016 or 2100. Equation (10) presents the calculation of the life cycle embodied energy of a building. The same equation is used to quantify water requirements and greenhouse gas emissions, simply by replacing energy terms by the corresponding quantity for water and emissions.

$L C E E_{b}=\underbrace{\sum_{m=1}^{M}\left(Q_{m, b} \times E C_{m}\right)}_{\mathbb{R} \in E_{b}}+\underbrace{\sum_{m=1}^{M}\left[\left[\frac{\left(T H-C Y_{b}\right)}{S L_{m}}-1\right] \times\left(Q_{m, b} \times E C_{m}\right)\right]}_{R E E_{b}}$

Where: $L C E E_{b}$ is the life cycle embodied energy of a building $b$ in GJ; IEE $E_{b}$ is the initial embodied energy of a building $b$ in GJ; $R E E_{b}$ is the recurrent embodied energy of a building $b$ in $G J, Q_{m, b}$ is the quantity of material $m$ in the building $b$, in functional unit (e.g. $\mathrm{m}^{3}$ of concrete); $E C_{m}$ is the hybrid energy coefficient of material $m$ in GJ per functional unit (see Equation (9)); $T H$ is the time horizon of the study (e.g. 2116); $C Y_{b}$ is the construction year of building $b$ (e.g. 1987) and $S L_{m}$ is the average service life of material $m$, in years.

The embodied requirements of the entire building stock are simply obtained by adding the requirements of each individual building, as per Equation (11) (for embodied energy). 


$$
\operatorname{LCEE}_{c}=\sum_{b=1}^{B} L_{C} E_{b}
$$

Where $L C E E_{c}$ is the life cycle embodied energy of a city $C$ in $G J$ and $L C E E_{b}$ is obtained as per Equation (10).

\subsection{Enabling decision making}

It is critical to empower stakeholders in the built environment with the necessary knowledge to make informed decisions that can eventually lead to an improved environmental performance at the building, neighbourhood and city scales. This is where spatialising the data provides significant insights into potential material stocks, future embodied energy and water needs and the environmental requirements of different types of developments and buildings. As advocated by Tanikawa and Hashimoto [11], there is a need for more research and information about "where and when material stocks cause flows and [in what] volume?" The presented model would provide answers to these questions and would go beyond the material dimension by introducing embodied requirements, which are largely understudied at the city scale [65]. By covering embodied energy, water, greenhouse gas emissions as well as materials and taking into account spatiality and temporality, the proposed model has the potential to enable city councils to make informed decisions in order to reduce waste, optimise material flows and reduce indirect environmental requirements. In order to illustrate this aspect, the model is applied to the City of Melbourne, Australia in the following section.

\section{Application of the proposed model to the City of Melbourne}

The City of Melbourne is an ideal case study to illustrate the potential of the framework. This is because it combines the access to open data, a recent building stock composed of materials for which the embodied requirements available are more realistic than for previous ones, a building stock size that is appropriate to test the bottomup approach and a land-use mix that is heterogeneous (for example, it is not a suburban precinct dominated by residential buildings). This section describes the city of Melbourne and the data available, discusses the methods used to process the data and derive particular archetypes and assemblies, and finally maps the material and embodied energy, water and greenhouse gas requirements, at both the city and the building level.

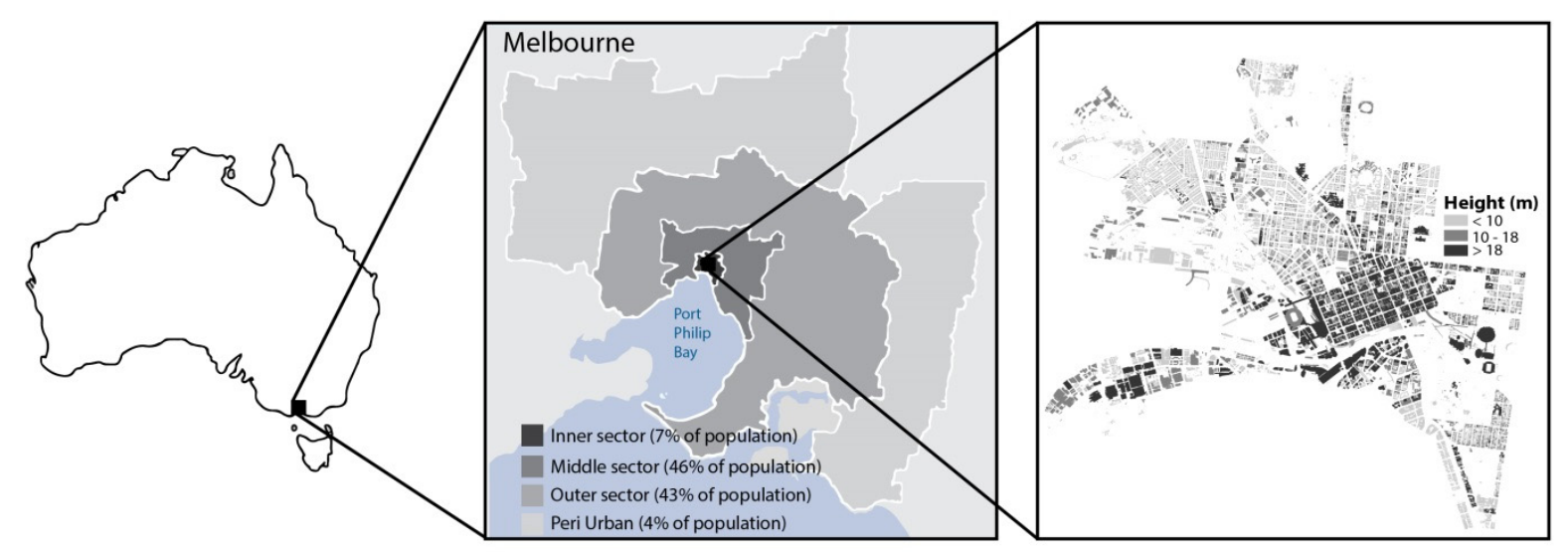

Figure 2: Location of Melbourne and map of the City of Melbourne with buildings differentiated by height. Note: The map of Melbourne is adapted from BITRE [67], and the City of Melbourne map is based on data from The City of Melbourne [68].

\subsection{Description and data availability}

The City of Melbourne represents most of the inner core of Melbourne, Australia, the second most populous city after Sydney with a population of 4 million inhabitants according to the latest census [66]. It is located in the southeast of Australia, at the North of Port Philip Bay. Melbourne is characterised by a dense CBD with high-rise buildings and sprawling low-density 
residential suburbs. The City of Melbourne council covers $36.2 \mathrm{~km}^{2}$ of land, comprises the CBD and its high-rise buildings and contains lowrise houses at its edges, as depicted in Figure 2 (Based on [67, 68])Since November 2014, The City of Melbourne has made an increasing number of publically available datasets, including data related to its building stock [69]. This makes it a data-rich city council with further data planned to be released, and which could be used in crossanalyses and to widen the scope of this study. In particular, the dataset used in this study was requested from the City of Melbourne and contains highly disaggregated data at the building level for the city council. The Census of Land Use and Employment (CLUE) database [68] contains the floor area by land-use, the age and the number of stories for each of the 14,385 buildings within the city council. In parallel to this dataset, this study relies on the footprints database of buildings (providing their spatial plan footprint). These two datasets had to be reconciled in this study in order to successfully apply our model (see Section 1.1 for details).

Another important property of the City of Melbourne is its relatively recent building stock because this is directly linked to the relevance of the embodied environmental requirements estimated. Indeed, according to the CLUE database, and for buildings for which a year of construction was provided (48\% of all buildings), more than $70 \%$ of the total floor area was constructed from 1960 onwards. If we assume that all buildings without a year of construction (52\%) are built between 1900 and 1960, as noted in the documentation of the database, this percentage remains larger than 55\% (based on data in the CLUE database). This makes the City of Melbourne a particularly relevant case study as the embodied environmental requirements quantified will be a much closer estimation of their actual value compared to cities with a much older building stock, such as in some European or Middle Eastern cities.

The variety of building types is another strong feature for considering the City of Melbourne as this allows a broad testing of the model, across multiple typologies. This is visible in Figure 3 which shows the built gross floor area by building typology for The City of Melbourne, based on data from the CLUE database [68]. While apartments and tertiary buildings represent a significant share of the stock, other building typologies are also present in non-negligible amounts. These typologies were derived from the land-use classification of the CLUE database, as explained in Section 1.1.

Gross floor area (Million $\mathrm{m}^{2}$ )

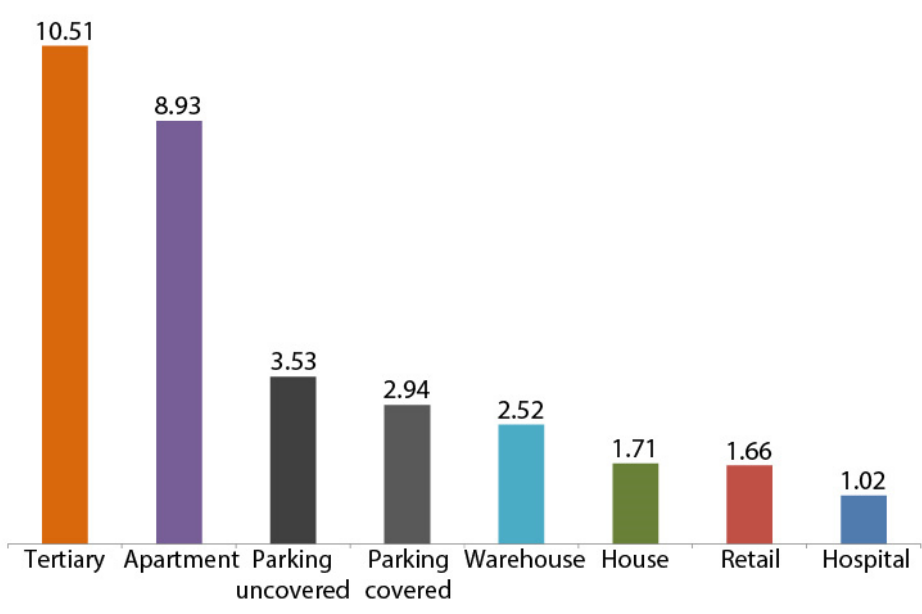

Figure 3: Gross floor area of the building stock of The City of Melbourne, by building typology. Based on data from [68]. Note: typology colours match those of Figure 4. 


\subsection{Method and data processing}

The model used to quantify material and embodied requirements for each building requires certain inputs that define the data processing required upstream. The model only accepts one land-use per building and a rectangular plan shape. This means that for each building within the CLUE database, a single landuse had to be determined. This was defined as the predominant land-use. From a physical perspective, the impacted assemblies are mostly related to finishes as structural assemblies are the same for a building, regardless of its use, and other assemblies, such as walls and windows, often use the same materials. Therefore attributing a single use to a building is not expected to significantly impact its overall material and embodied requirements, notably where most of the building is linked to a certain land-use (e.g. $85 \%$ of the gross floor area of the building is used for offices). In addition, the CLUE database provides a breakdown into 38 different land-use categories. Many of these categories can be aggregated within the scope of this research. Some categories which were not relevant or did not represent significant material requirement (e.g. Open space outdoor) were discarded and others were systematically reattributed to the predominant land-use within each building (i.e. common areas, spaces under renovation and unoccupied spaces) (see Figure 4). This assumes that such areas use the same assemblies as the predominant land-use. Once a single CLUE database land-use was attributed to each building, these were then clustered by building typology. A set of 48 different building archetypes were then generated based on building typology, construction year and height. The different categories used for the building ages were based on Fuller and Crawford [70] for residential houses and on Seo et al. [71] for other uses. This not only provides coherence with other studies published on Melbourne and the City of Melbourne, but enables the future integration of embodied and operational energy results. Warehouse archetypes were only attributed two different years to determine their assemblies and parking were assumed to use the same assemblies, regardless of their year of construction. For each archetype, a set of building assemblies were defined based on expert knowledge in construction and architectural history. The list of all archetypes used, the characteristics of each and the details of all assemblies used, as well as their material compositions are accessible openly on Figshare (Stephan and Athanassiadis [72] and Stephan and Athanassiadis [73], respectively). It is important to note that when a building had an underground parking, the latter was modelled separately and then integrated to the building. This is to avoid underground parkings being converted to the predominant land-use which would have significantly different assemblies. Furthermore, all buildings with a predominant land-use of 'Parking' resulting from the data manipulation process have been manually verified to ensure correctness and reattributed to the second largest land-use were relevant. Figure 4 depicts the process used to convert the original CLUE database land-uses to archetypes. This process covers the assemblies and archetypes stream of the overall model depicted in Figure 1 as well as the data feed from the CLUE database into the 'Land use areas per building' process.

In parallel to the process of identifying archetypes and defining associated assemblies, the geometric characteristics of each building (width, depth, height) need to be determined and provided as input to the model. These quantities were determined using a range of data from both the building footprints database and the CLUE database. As a starting point, all buildings with a footprint of $40 \mathrm{~m}^{2}$ or less were discarded as they are not suitable to be modelled using the developed archetypes and often correspond to small structures or small buildings such as kiosks, public storage areas, etc. These represent less than $1 \%$ of the total footprint area and much less of the total floor area. In addition to these buildings, all building typologies that were not considered (see Figure 4) were also removed from the dataset, i.e. stadiums, train stations, racecourses, etc. Once the dataset has been filtered, the perimeter and area of each building were extracted from the building footprints. The floor area was then compared to what is listed in the CLUE database. Many discrepancies were noted in this comparison, revealing the need for more consistent databases in order to reduce 
uncertainty. The areas reported in the CLUE database were used in order to ensure consistency and because these are believed to be more accurate. However, this means that there can be a potential mismatch between the area of a building and its perimeter. More importantly, the footprints database had a lower resolution than the CLUE in terms of building counts and this means that some building had to be clustered together by address in order to be able to represent them on a map. These uncertainties are further discussed in Section 4.3.

An optimisation algorithm was used to calculate the width and depth of each building. Optimisation is a widely recognised and established method in the field of engineering and has been used for a range of applications, ranging from structural optimisation [74] to precipitation analysis [75]. Optimisation is needed because using a quadratic equation to calculate the width and length pair that matches a certain area-perimeter combination can generate solutions that do not represent realistic building configurations, e.g. a building with a width of $2 \mathrm{~m}$ and a length of $42 \mathrm{~m}$. In order to palliate to this issue, the constrained optimisation by linear approximation algorithm developed by Powell [76-78] and implemented on Scientific Python was used to obtain width-length pairs that meet a set of constraints. The objective function was set to obtain the same floor area for the building as floor area is the building parameter that influences the most its material stock and therefore its other embodied environmental requirements. The constraints included a perimeter within a $5 \%$ margin of the original perimeter (the perimeter has a significant impact on the vertical assemblies) and a length to width ratio between 1 and 5 . The assumption is that the very large majority of buildings will fit into this ratio. All the constraints could not be met by the algorithm, notably because of the discrepancies between the datasets used. This resulted in a slight overestimation of the floor area (on average $+3 \%)$ and a slight underestimation of the total perimeter of buildings (on average -7\%). However, these deviations are judged acceptable given the large building sample and much larger uncertainties in the data, although they need to be kept in mind when discussing or comparing results from this study. The number of storeys for each building is provided in the CLUE database and is multiplied by an average floor height by building typology to obtain the total building height. The process explained above covers the building geometry stream in Figure 1. 
This is the accepted version of the manuscript accepted in Building and Environment. For the full paper please go to : http://dx.doi.org/10.1016/j.buildenv.2016.11.043 or lookup the paper on Google Scholar

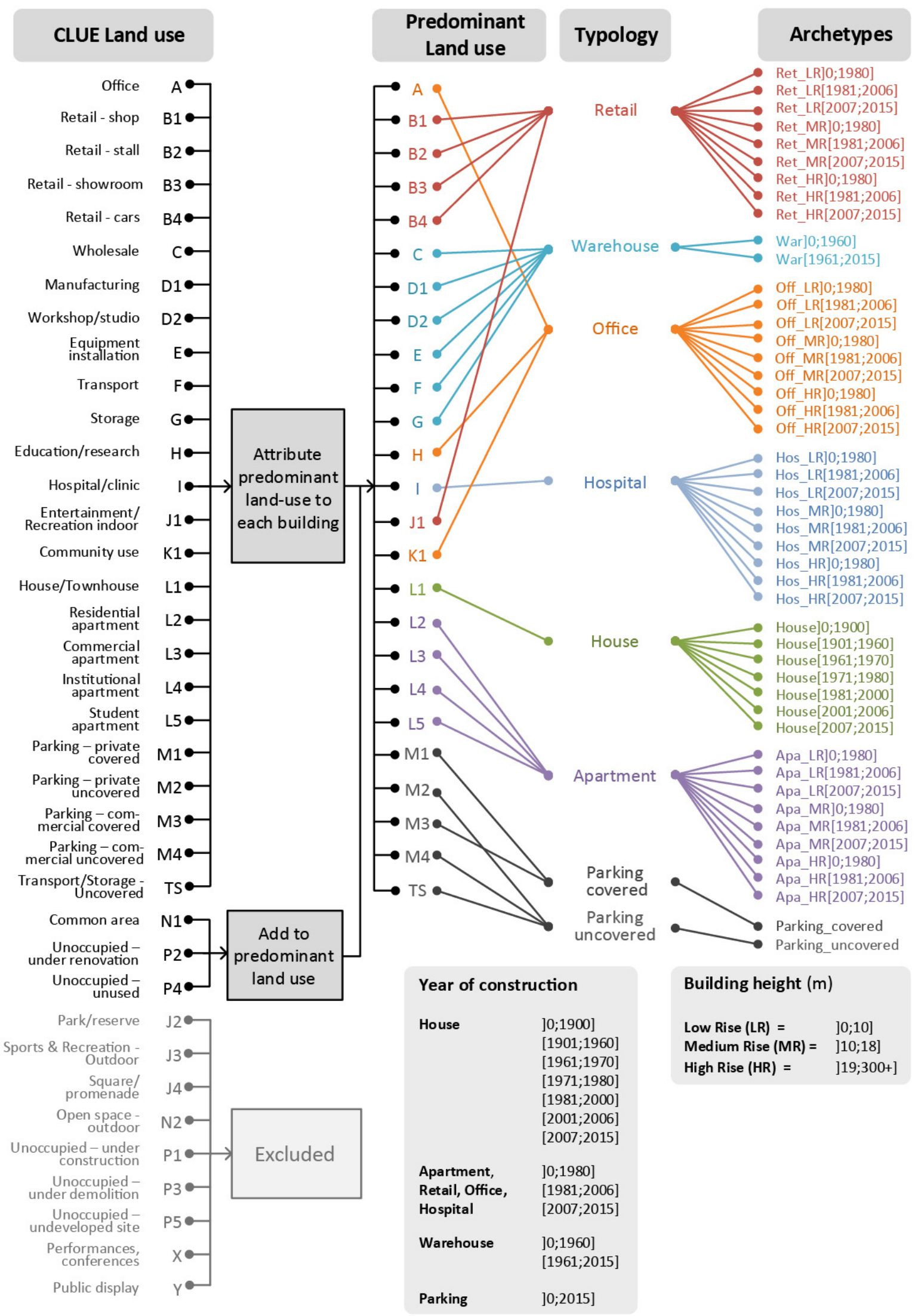

Figure 4: Data processing used to convert CLUE database land-uses into building archetypes. Note: typology colours match those of Figure 3. 
Once the archetypes and assemblies data as well as the geometric data were ready, they were matched with embodied requirements data (see Section 2.4) and fed into the model. The total number of buildings simulated totalled 13075 (out of the 14385 initial buildings), excluding underground parking. With an average of 4 seconds of calculations per building, the total simulation time was around 14 hours and 30 minutes on a quad-core i7 intel processor with 16 GB RAM. The results were directly generated as spreadsheets which were used to spatialise embodied environmental requirements for the City of Melbourne, as shown in Section 3.3.

\subsection{Results}

The results of the application of the proposed model to the City of Melbourne are presented in this section to illustrate the potential of the framework. The results presented include initial, recurrent and life cycle material and embodied requirements, spatialised per building and at the entire city level. Instead of performing an in depth analysis of each result, the purpose of this section is to demonstrate the breadth of outputs that the model can generate in order to provide material for the discussion section.

Figure 5 depicts the spatial representation of initial embodied requirements. These intensities correspond to the requirements associated with the initial construction of the building stock, calculated using embodied requirements coefficients. They do not account for the change of energy, water and greenhouse gas intensity according to the construction year. The zoomedin portions of the energy and water maps reveal the resolution of the model. Such intensities do not offer a significant scope for improvement, even if they were extremely accurate and detailed, since the environmental impact resulting from these requirements has already occurred. However, they do provide an estimation of the overall requirements needed for building new cities which are similar in stock composition to the city of Melbourne. The inclusion of initial embodied requirements in the model allows the comparison of different urban forms, should these be built today. This can inform urban design and planning of new cities or neighbourhoods.

More interesting results are depicted in Figure 6, which represents the distribution of the quantity of a certain material across the buildings of the city. Such maps provide significant decisionmaking support for material recycling, waste management and urban mining, as indicated in Tanikawa and Hashimoto [11], Zhu [46] and \{Kleemann, 2016 \#1577@@author-year\}. Providing high resolution material distribution maps that are based on an engineering bottomup approach would inform decision-makers about where certain materials are likely to be replaced and most importantly, in what quantities. These maps are only snapshots of the total quantities but the model allows the generation of dynamic maps depicting which quantities of materials in which buildings are expected to have reached their end of life for a particular year or for a year band, adding the critical time dimension to inform decisions. This is enabled in the model through the detailed modelling of materials and assemblies which departs from most existing approaches to model buildings stocks.

Apart from high resolution spatialised results, the model quantifies the total energy, greenhouse emissions, water and material requirements of the building stock over time, as depicted in Figure 7. The latter shows the total initial and recurrent requirements by assembly, for all buildings in the City of Melbourne. Such measurement could not be found in the existing literature and a number of observations can be made. Note that forecasted recurrent requirements assume a constant building stock without any demolition or addition of buildings. These requirements are needed to maintain the current building stock of the City of Melbourne until 2100. 


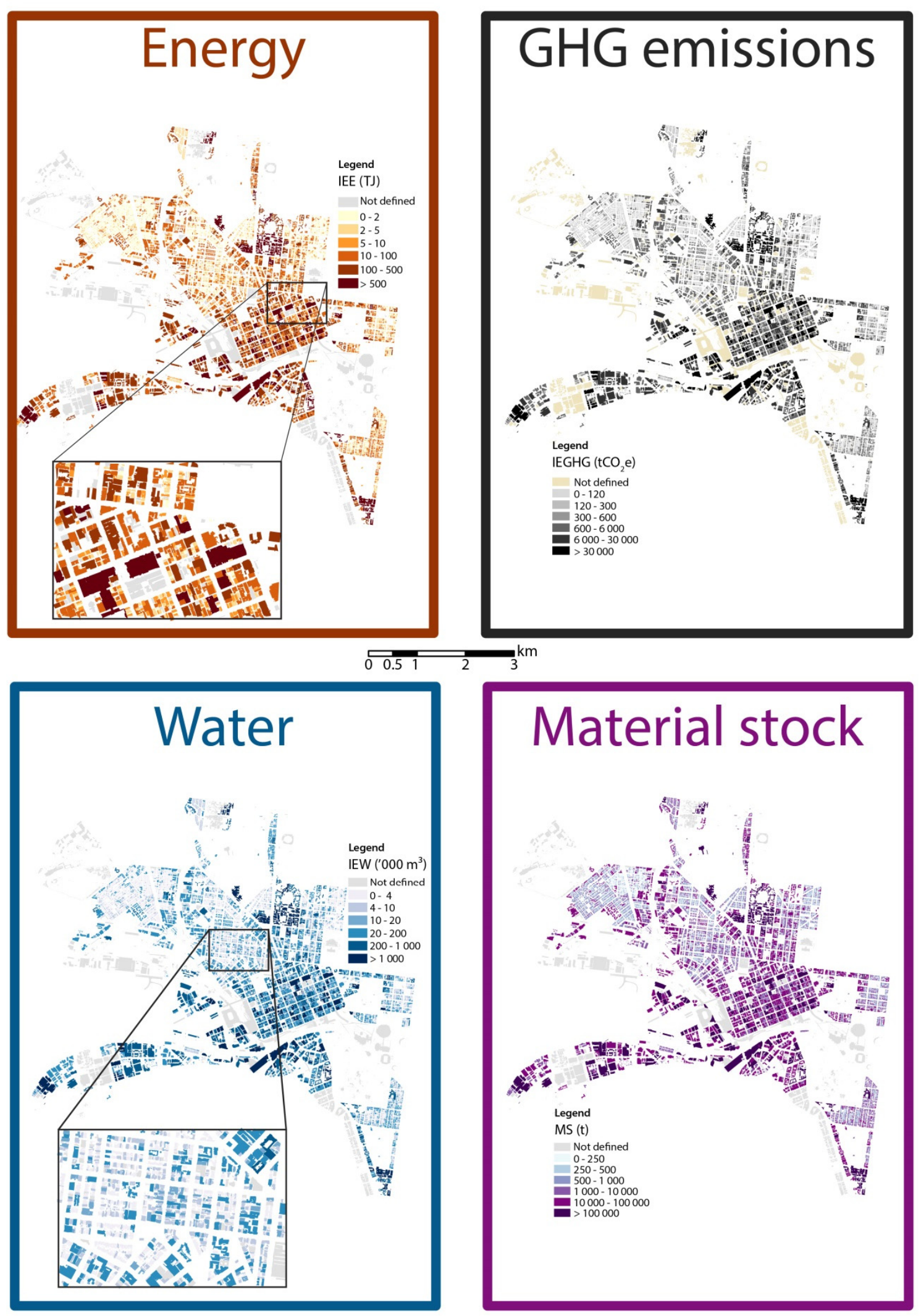

Figure 5: Initial embodied requirements of the City of Melbourne, by flow. Note: IEE: initial embodied energy; IEGHG: initial embodied greenhouse gas emissions; IEW: initial embodied water and MS: material stock. 


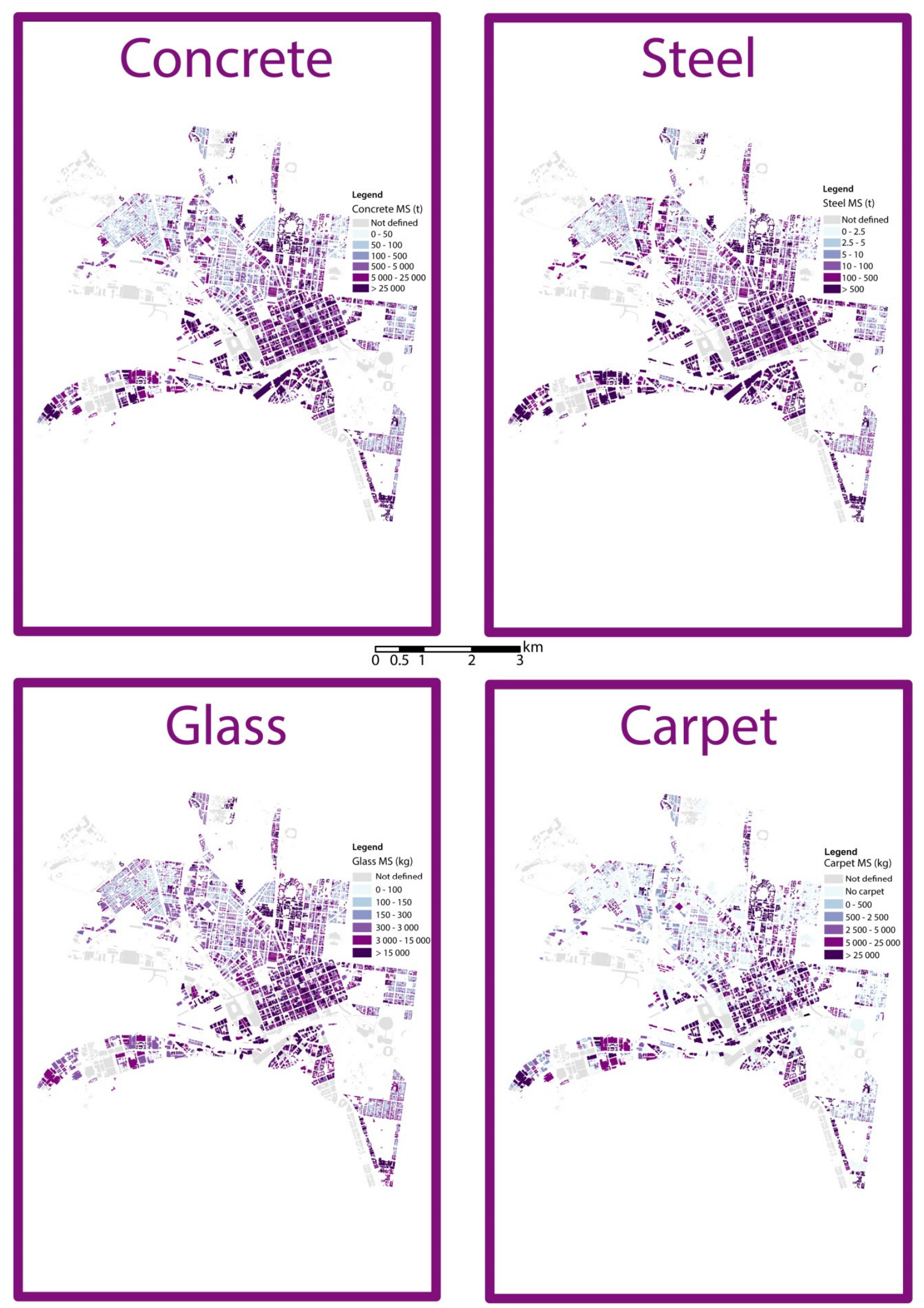

Figure 6: Current estimated material stock of the City of Melbourne, for selected materials. Note: MS: Material stock. 
Firstly, the significance of embodied requirements should be noted. For example, the initial embodied energy of reinforced concrete slabs alone represents 115.7 PJ which is equivalent to $\sim 8$ years of electricity demand for the City of Melbourne and the city councils of Port Philip, Stonnington and Yarra, combined (based on an annual electricity demand of 4524 GWh (16.28 PJ), from figures reported in Seo et al. [71]). The total estimated life cycle embodied water demand until 2100 represents 52.2 billion $\mathrm{m}^{3}$ which is equivalent to filling the surface of the City of Melbourne with $1450 \mathrm{~m}$ of water, as high as some of the mountains in the Victorian Alps, Australia.

Secondly, the comparison of initial, recurrent to date and forecasted recurrent requirements until 2100 demonstrates the significance of material service life on material flows and recurrent embodied requirements at the city level. Structural assemblies, made of materials that last as long as the building, represent the majority of the initial demand. However, as buildings last, originally insignificant assemblies and materials, such as carpet, represent an increasing relative and absolute share of the total. On a longer time frame, such materials represent the largest share of embodied requirements, as shown by the requirements associated with flooring. While such findings have been reported before at a building level (see $[79,80]$ ) this study demonstrates the potential magnitude of recurrent embodied requirements at a city scale. The implications of this observation are further discussed in Section 4.1.

Thirdly, Figure 7 demonstrates the need to present multiple indicators simultaneously in order to more comprehensively capture the multi-faceted environmental effects of the built environment. Indeed, most existing studies at the city level focus solely on material flow analysis, using $\mathrm{kg}$ or tonnes as a unit. Looking at the bottom bar chart which represents materials, the majority of the weight is concentrated in structural assemblies, notably reinforced concrete slabs, as would be expected. However, when these quantities are converted to environmental requirements, the significance of envelope, finishes and other assemblies increases at the expense of structural assemblies because the environmental requirements associated with the materials used in these assemblies are higher than those used in structural assemblies. The average service life of such assemblies is also shorter, resulting in more frequent replacements.

This in depth analysis at an assembly level results from considering assemblies in the model, and not only materials. It provides significant scope to identify the most critical assemblies, their potential for material recovery and how to design them for optimal life cycle resource use. Since many construction assemblies are manufactured and sold packaged, e.g. windows, doors, prefabricated walls and others, the assembly level is critical for decision-making.

It is important to highlight that the intensity of embodied requirements can vary dramatically through time. The extraction of materials, their manufacturing, processing and transport to site as well as construction techniques have evolved and will most probably evolve significantly across the long time period covered in this study. Assuming a fixed environmental intensity is highly unrealistic. However, there is very little data regarding the previous embodied requirements of building materials and little added value for this research in attempting to quantify these. Forecasting future embodied requirements could be performed using 'what-if scenarios' [81] and this could be easily implemented in the model. This would allow a better evaluation of the range of environmental requirements that future material replacements could represent. The data in Figure 7 should therefore be interpreted as indicative at best. Only the initial embodied requirements of recently constructed buildings and recurrent embodied requirements within a 10-20 years timeframe around the release date of the embodied requirements database are reliable. Uncertainty in the data increases as the time horizon moves away from this window, but given that most of Melbourne's building stock is built after 1960 (see Section 3.1), the deviation from actual figures is expected to be less than in other older cities. The quantities of materials do not suffer from this time dependency as much because they have been determined based on 
the construction year of each building, among other factors (see Section 1.1).
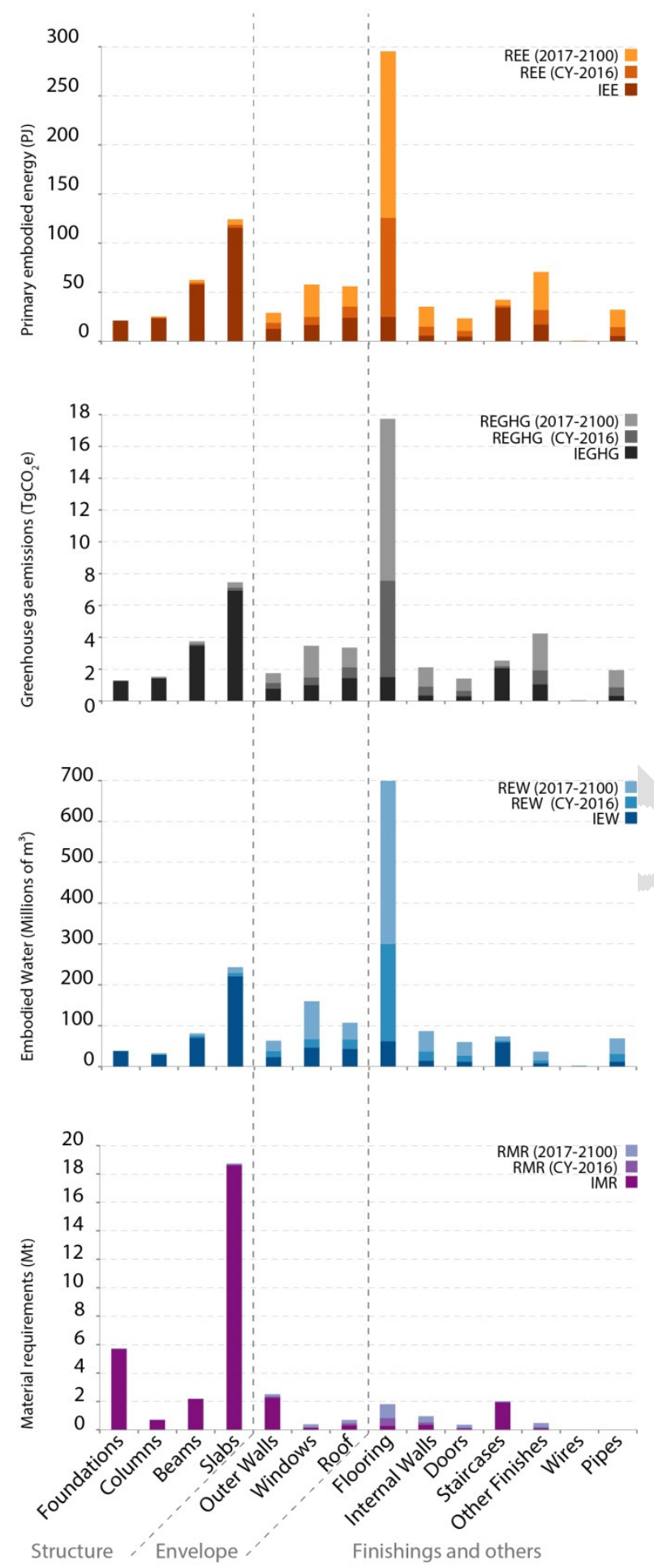

Figure 7: Life cycle embodied requirements of the City of Melbourne, by flow and by assembly. Note: IEE: initial embodied energy; IEGHG: initial embodied greenhouse gas emissions; IEW: initial embodied water; IMR: initial material requirement; REE: recurrent embodied energy; REGHG: recurrent embodied greenhouse gas emissions; REW: recurrent embodied water; RMR: recurrent material requirement; and $\mathrm{CY}$ : construction year of each building.

Figure 8 represents the evolution of the accumulated requirements to maintain the current building stock regarding carpet weight, total life cycle embodied water, energy, greenhouse gas emissions and material weight until 2100, with 2015 as a reference year. This graph reinforces the third observation made on Figure 7: quantifying the material stock should be accompanied by other indicators and should also be broken down by assembly or material. The frequent replacement of carpets in time shows a constant flow of carpet which results in significant recurrent embodied requirements. Extending material service lives or relying on more durable materials can help reduce the annual recurrent material requirements and associated embodied requirements. The developed model can be used to run scenarios that evaluate the effect of replacing certain materials by others on embodied environmental requirements.

This section has provided an overview of the multiple outputs and results that the proposed model can generate. Section 4 discusses these results. 


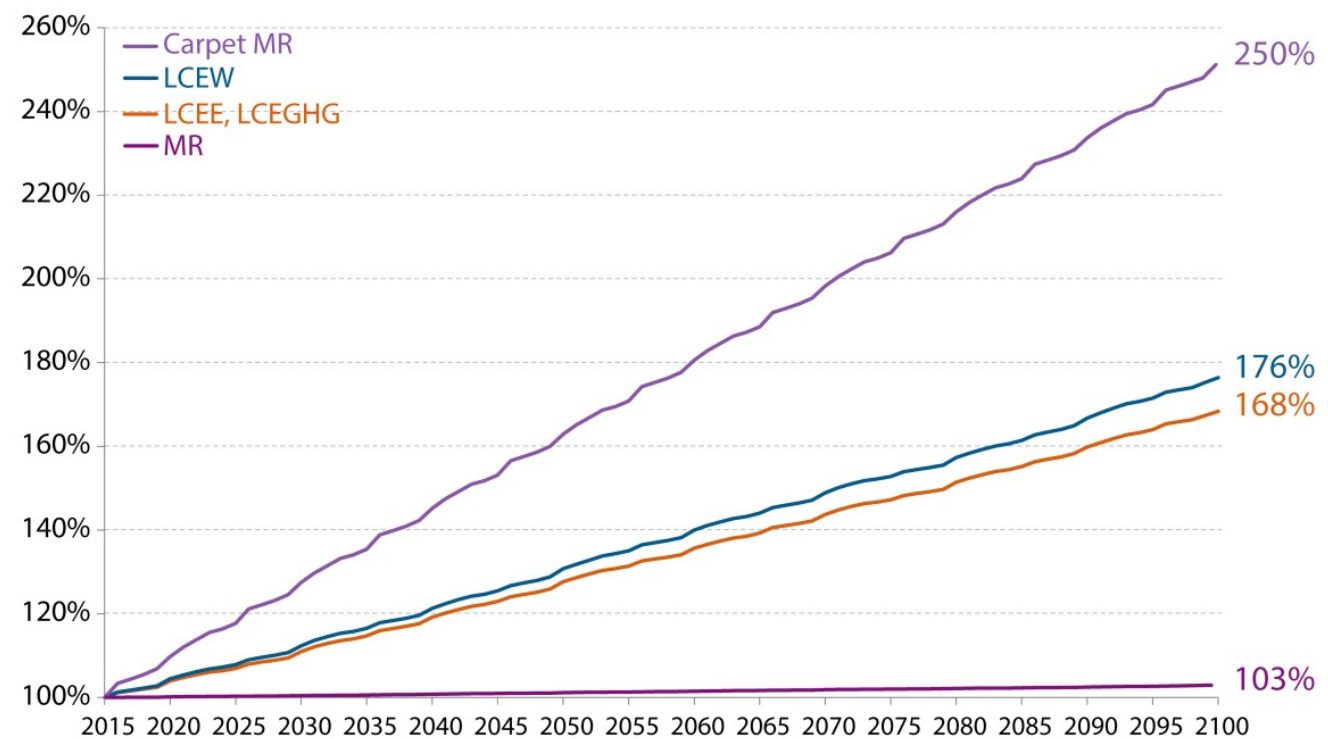

Figure 8: Forecasted embodied requirements until 2100, by flow. Note: $2015=100 \%$; MR: Material requirements; LCEW: life cycle embodied water; LCEE: life cycle embodied energy; and LCEGHG: life cycle embodied greenhouse gas emissions.

\section{Discussion}

This section discusses the model presented in Section 2 and its application to the City of Melbourne in Section 3. It covers the contribution of this study to the body of knowledge as well as the usefulness of the model and its relevance to inform future environmental decision making in cities. The limitations of the model and associated future research directions are also discussed.

\subsection{Informing future environmental decision making in cities}

This study has proposed a model to quantify and spatialise embodied environmental requirements of building stocks. It provides an unprecedented level of detail in terms of material stock modelling and provides opportunities for further data enrichment. The application of the model to the City of Melbourne, Australia demonstrates the breadth of information that can be provided and the sometimes counterintuitive results that emerge from a detailed bottom-up modelling, e.g. flooring assemblies could be responsible for the largest embodied requirements at a 2100 horizon.

The model proposed follows previous attempts to model the building stock of cities [11-13, 15] but provides a more detailed approach to material quantity estimation. While material quantities at a building level are still expected to possibly differ significantly from reality, the format of the model allows the replacement of particular quantities for a specific building with actual figures. More importantly, this level of detail allows decision makers to trace back embodied environmental requirements to materials and assemblies, which is rarely available in existing studies.

By capturing embodied requirements and spatialising these as well as material stocks, urban decision-makers can improve the environmental management of cities. For instance, they can anticipate periods of potential material replacement in a certain area based on the information provided in the model and optimise recycling, urban mining and resource and waste management. With materials being depleted at an increasing rate [5], the urban mining of valuable materials can be facilitated by using a spatialised model that includes expected replacement rates. In their study on mining copper from the electric grid of Linköping, Sweden, Wallsten et al. [82] demonstrate the potential of combining high spatial resolution with infrastructure material stock models. From a waste management perspective, the proposed model provides a much higher resolution compared to other GIS-based models that often focus on a regional or national level, such as $\mathrm{Wu}$ 
et al. [83]. In the case of the building stock of the City of Melbourne, the significance of carpet in terms of embodied requirements offers great opportunities in terms of circular economy. Questions such as: 'how can value be added to used carpets?' or 'how can carpets be upcycled?' are critical as this material is responsible for significant resource flows across time. Studies such as Realff et al. [84] provide the basis for answering such questions but other avenues, beyond recycling, should be explored. Furthermore, modelling materials within assemblies provides valuable information on the potential quality of the material when it needs to be replaced, which is critical [85]. This can inform where materials suitable for a particular reuse or recycling process can be found and when. The proposed tool captures the multiple parameters required to effectively measure and inform embodied requirements of buildings stocks: the 3D geometry of buildings, their location within the city, their detailed assembly and material compositions and the passing of time.

The model fills a knowledge gap by quantifying embodied energy, water and greenhouse gas emissions at the city scale. As shown in Allegrini et al. [20], there are currently no models that quantify embodied environmental requirements of building stocks at the city level. By applying the bottom-up approach to the City of Melbourne, this paper generates critical knowledge for the construction of new cities. For example, rebuilding the City of Melbourne's building stock today, which weighs $904 \mathrm{kt} / \mathrm{km}^{2}$, would require 10 $\mathrm{PJ} / \mathrm{km}^{2}, 605 \mathrm{ktCO}{ }_{2} \mathrm{e} / \mathrm{km}^{2}$ of embodied greenhouse gas emissions and 17.7 Million $\mathrm{m}^{3} / \mathrm{km}^{2}$ of embodied water. These figures could be used to estimate the environmental pressure of constructing new cities or new developments. In addition, these figures tend to reveal that socalled 'zero-carbon' developments often still require a significant amount of resources to build and maintain throughout their lifecycle. The intensity of these figures is demonstrated in comparison to those found by Stephan et al. [44] for a low-density suburb near Melbourne, Australia, and which totalled 8-10 $\mathrm{PJ} / \mathrm{km}^{2}$ for the initial and recurrent embodied energy of buildings and infrastructure, the operational energy (including heating, cooling, lighting, hot water, cooking and appliances) and the usertransport energy (cars) over 100 years. The initial embodied energy intensity of the building stock of the City of Melbourne (excluding infrastructures) is therefore equal to the life cycle energy demand intensity of an entire suburban residential neighbourhood, over 100 years. This is a conservative estimate as many buildings were not considered in this study and results are based on process-based hybrid analysis which, while more comprehensive than process and inputoutput analysis, still underestimates embodied requirements compared to input-output-based hybrid analysis.

\subsection{Applying the model to other cities}

The parametric nature of the model allows its application to any other city, as long as the needed data are available. This is the case of many cities that provide open-access data on their building stock. The following five datasets are required to apply the proposed framework to another city:

1. The geometry of each building within a GIS shape file (ideally) or simply as floor area, perimeter, height or number of stories, and number of façades;

2. The age of construction of each building;

3. The typology of each building (i.e. office, retail, residential, etc.);

4. The assemblies that correspond to each typology-age combination (these need to be established in consultation with architectural historians and construction experts); and

5. A database of coefficients of material embodied requirements that includes average material services lives and is geographically relevant (this fifth database is used to derive embodied requirements and is not required for material stock modelling which can be obtained from the four previous datasets).

The first four datasets should then be fed into the calculation model (see Figure 1) to determine the material building stock at a very high resolution providing results per material, assembly and building. Embodied requirements can be 
calculated using the fifth dataset. The first three datasets can be obtained relatively easily in many cities, for example based on cadastral data (although sometimes these data can be confidential or expensive to access). The fourth dataset requires expert knowledge and would typically need to be developed from scratch for each case study according to the construction age groups chosen by the assessors for each typology. However, this is feasible and would allow the bottom-up quantification of the building stock of many cities. Deriving embodied requirements can suffer from huge levels of uncertainty and depends exclusively on the fifth dataset. More research is needed to produce more reliable databases of embodied requirements for construction materials and other products, using the most advanced life cycle inventory techniques, such as multi-regional input-output-based hybrid analysis. The limitations of the study are further discussed in the following section.

\subsection{Limitations and future research}

Any model is an attempt to represent reality [86]. The proposed model is no exception to this rule and suffers from a number of limitations. These can be clustered into three main categories: uncertainty, system boundaries and data intensity.

Uncertainty is the most significant limitation of the model and it stems from a number of parameters, including database mismatches and data encoding errors from third party material; archetypes definitions, assemblies definitions and bill of material quantity estimation algorithms; and finally from embodied environmental intensities of materials. Since the model quantifies indicators that are dependent on a series of upstream calculations, uncertainty is propagated across the model and increases at every calculation. The most uncertain results are embodied environmental requirements, followed by building material quantities and then by building floor areas. It is important to highlight that not all building material quantities suffer from the same level of uncertainty. Structural and envelope assemblies and materials are likely to be determined with a high level of certainty as most buildings constructed during a certain time period tend to follow industry trends. This tends to be particularly valid in developed economies where a few main developers and major contractors are responsible for the construction of the majority of the building stock and typically rely on similar construction techniques for economies of scale. However, less critical assemblies, such as finishes, depend much more on user choice and are much more variable from building to building. Their assignment therefore suffers from a much higher degree of uncertainty. Given that such assemblies are typically replaced more frequently and result in significant environmental requirements across time (e.g. carpets), the uncertainty associated with these requirements is also very high. One way to evaluate the magnitude of assigning such assemblies is to consider a range of scenarios that cover different materials and different replacement rates. This would result in minimum and maximum requirements that provide a band where the actual figure is likely to lie within. Another major challenge with this model is that it is impossible to validate the results as there are no other studies that evaluate the embodied environmental requirements of building stocks nor is it possible to physically measure them. The obtained material stock intensity of $904 \mathrm{kt} / \mathrm{km}^{2}$ is however aligned with what is reported in previous studies, e.g. $1118 \mathrm{kt} / \mathrm{km}^{2}$ in Tanikawa and Hashimoto [11] for Salford, United Kingdom. Since their study also included infrastructures, the difference in the intensities for the building stock only is expected to be relatively small, which adds confidence to the results obtained. Furthermore, the material intensity per square metre of built area ranges between $210-9611 \mathrm{~kg} / \mathrm{m}^{2}$ and falls in line with the magnitudes found for Vienna (0$24000 \mathrm{~kg} / \mathrm{m}^{2}$ ) by Kleemann et al. [50] However, this does not allow any kind of verification of the calculation of particular materials or assemblies quantities.

The second limitation of the model is its focus on the building stock only, omitting infrastructures. Previous studies on material stock modelling (e.g. [13]) and the environmental assessment of cities (e.g. [45]) found that the embodied requirements of infrastructures can be significant. Adding this component to the model is therefore a priority in terms of future research. Incorporating additional 
indicators, such as pollutants would also improve the model and improve its capacity to support decision making. Most importantly, the model should be extended to cover the entire life cycle stages of buildings, including their operation. This will ensure that reducing embodied requirements does not result in simply shifting environmental effects to other life cycle stages. As mentioned in Section 2.1, the model used already incorporates operational and transport requirements for residential buildings and can be modified in the future to model other building types and provide a more comprehensive bottom-up life cycle assessment of cities.

In addition to the above limitations, the data intensive nature of the model reduces its potential widespread application. Additional streamlined databases of embodied requirements intensities for materials, assemblies compositions and building footprints and land-uses would help facilitate the widespread adoption of such models by city councils and other relevant stakeholders in order to improve the environmental performance of cities.

\section{Conclusion}

The embodied environmental requirements of building stocks have rarely been evaluated while being responsible for significant environmental damage. This study proposes a bottom-up modelling approach to quantify and spatialise embodied requirements of building stocks, including material use, energy use, greenhouse gas emissions and water use. The application of the model to the City of Melbourne, Australia confirms the significance of embodied requirements and illustrates the potential of the model through the breadth of outputs it generates. While results suffer from uncertainty, the model can be gradually enriched with higher quality data to minimise the latter. The proposed model can help city councils quantify and evaluate material and environmental flows and better manage their cities in terms of waste and urban mining. This will ultimately help improve resource efficiency and reduce the environmental damage cause by the built environment.

\section{Acknowledgements}

This research was funded by an Early Career Researcher grant, the Graham Treloar Fellowship and a conference travel grant from the Faculty of Architecture, Building and Planning, The University of Melbourne. Aristide Athanassiadis was funded through a research fellowship (aspirant FNRS) from the Belgian Fund for Scientific Research F.R.S.-FNRS, a WBI World excellency scholarship and a BRIC scholarship.

\section{References}

[1] Grubler A, Bai X, Buettner T, Dhakal S, Fisk DJ, Ichinose $T$, et al. Chapter 18 - Urban Energy Systems. Global Energy Assessment - Toward a Sustainable Future. Cambridge University Press, Cambridge, UK and New York, NY, USA and the International Institute for Applied Systems Analysis, Laxenburg, Austria2012. p. 1307-400.

[2] IPCC. Climate change 2014: mitigation of climate change. Contribution of working group III to the fifth assessment report of the intergovernmental panel on climate change. In: Edenhofer O, Pichs-Madruga R, Sokona Y, Minx JC, Farahani E, Kadner S, et al., editors. Cambridge: Cambridge University Press; 2014.

[3] Horvath A. Construction Materials and the Environment. Annual Review of Environment and Resources. 2004;29:181-204.

[4] EC. Construction and Demolition Waste (CDW). European Comission, Available from http://ec.europa.eu/environment/waste/construc tion demolition.htm, 17/06/2016, 2016 (Accessed 10/08 2016).

[5] UNEP. Global Material Flows and Resource Productivity. An Assessment Study of the UNEP International Resource Panel. Paris: United Nations Environment Program; 2016.

[6] U.N. World urbanization prospects: the 2011 revision. In: Department of Economic and Social Affairs, editor. New York: United Nations; 2012. p.318.

[7] Kennedy C, Cuddihy J, Engel-Yan J. The Changing Metabolism of Cities. J Ind Ecol. 2007;11:43-59.

[8] Zhang Y. Urban metabolism: A review of research methodologies. Environmental Pollution. 2013;178:463-73.

[9] Athanassiadis A, Bouillard P, Crawford RH, Khan AZ. Towards a Dynamic Approach to Urban 
Metabolism: Tracing the Temporal Evolution of Brussels' Urban Metabolism from 1970 to 2010. J Ind Ecol. In Press.

[10] Athanassiadis A, Crawford RH, Bouillard P. Overcoming the "black box" approach of Urban Metabolism. In: Crawford RH, Stephan A, editors. Living and Learning: Research for a Better Built Environment, 49th International Conference of the Architectural Science Association. Melbourne, Australia: The Architectural Science Association and The University of Melbourne; 2015. p.547-56.

[11] Tanikawa H, Hashimoto S. Urban stock over time: spatial material stock analysis using $4 \mathrm{~d}-\mathrm{GIS}$. Build Res Inf. 2009;37:483-502.

[12] Marcellus-Zamora KA, Gallagher PM, Spatari $\mathrm{S}$, Tanikawa H. Estimating Materials Stocked by Land-Use Type in Historic Urban Buildings Using Spatio-Temporal Analytical Tools. J Ind Ecol. 2015:n/a-n/a.

[13] Tanikawa H, Fishman T, Okuoka K, Sugimoto K. The Weight of Society Over Time and Space: A Comprehensive Account of the Construction Material Stock of Japan, 1945-2010. J Ind Ecol. 2015;19:778-91.

[14] Hu D, You F, Zhao Y, Yuan Y, Liu T, Cao A, et al. Input, stocks and output flows of urban residential building system in Beijing city, China from 1949 to 2008. Resources, Conservation and Recycling. 2010;54:1177-88.

[15] Fishman T, Schandl H, Tanikawa H, Walker P, Krausmann F. Accounting for the Material Stock of Nations. J Ind Ecol. 2014;18:407-20.

[16] Keirstead J, Jennings $M$, Sivakumar A. A review of urban energy system models: Approaches, challenges and opportunities. Renewable and Sustainable Energy Reviews. 2012;16:3847-66.

[17] Howard B, Parshall L, Thompson J, Hammer S, Dickinson J, Modi V. Spatial distribution of urban building energy consumption by end use. Energ Buildings. 2012;45:141-51.

[18] Reinhart CF, Cerezo Davila C. Urban building energy modeling - A review of a nascent field. Building and Environment. 2016;97:196-202.

[19] Kavgic M, Mavrogianni A, Mumovic D, Summerfield A, Stevanovic Z, Djurovic-Petrovic M. A review of bottom-up building stock models for energy consumption in the residential sector. Building and Environment. 2010;45:1683-97.
[20] Allegrini J, Orehounig K, Mavromatidis G, Ruesch F, Dorer V, Evins R. A review of modelling approaches and tools for the simulation of district-scale energy systems. Renewable and Sustainable Energy Reviews. 2015;52:1391-404.

[21] Cole RJ, Kernan PC. Life-cycle energy use in office buildings. Building and Environment. 1996;31:307-17.

[22] Feist W. Life-cycle energy balances compared: low-energy house, passiv house, selfsufficient house. Proceedings of the International Symposium of CIB W67. Vienna, Austria: CIB W67; 1997. p.183-90.

[23] Adalberth K. Energy use during the life cycle of single-unit dwellings: Examples. Building and Environment. 1997;32:321-9.

[24] Sartori I, Hestnes AG. Energy use in the life cycle of conventional and low-energy buildings: A review article. Energ Buildings. 2007;39:249-57.

[25] Ramesh T, Prakash R, Shukla KK. Life cycle energy analysis of buildings: An overview. Energ Buildings. 2010;42:1592-600.

[26] Karimpour M, Belusko M, Xing K, Bruno F. Minimising the life cycle energy of buildings: Review and analysis. Building and Environment. 2014;73:106-14.

[27] Crawford RH. Validation of a hybrid life-cycle inventory analysis method. J Environ Manage. 2008;88:496-506.

[28] Majeau-Bettez G, Strømman AH, Hertwich EG. Evaluation of process- and input-output-based life cycle inventory data with regard to truncation and aggregation issues. Environ Sci Technol. 2011;45:10170-7.

[29] Dixit MK, Culp CH, Fernandez-Solis JL. Embodied Energy of Construction Materials: Integrating Human and Capital Energy into an IOBased Hybrid Model. Environ Sci Technol. 2015;49:1936-45.

[30] Crawford RH. Life cycle assessment in the built environment. London: Spon Press; 2011.

[31] Crawford RH, Stephan A. The significance of embodied energy in certified passive houses. ICCBM 2013: International Conference on Construction and Building Materials. Copenhagen: World Academy of Science, Engineering and Technology; 2013. p.473-9.

[32] Stephan A, Stephan L. Reducing the total life cycle energy demand of recent residential buildings in Lebanon. Energy. 2014;74:618-37. 
[33] Treloar GJ. Extracting embodied energy paths from input-output tables: towards an inputoutput-based hybrid energy analysis method. Econ Systems Res. 1997;9:375-91.

[34] Stephan A, Crawford RH. A comprehensive life cycle water analysis framework for residential buildings. Build Res Inf. 2014;42:685-95.

[35] Blengini GA, Di Carlo T. The changing role of life cycle phases, subsystems and materials in the LCA of low energy buildings. Energ Buildings. 2010;42:869-80.

[36] Crawford RH, Bartak EL, Stephan A, Jensen CA. Evaluating the life cycle energy benefits of energy efficiency regulations for buildings. Renewable and Sustainable Energy Reviews. 2016;63:435-51.

[37] Anderson JE, Wulfhorst G, Lang W. Energy analysis of the built environment-A review and outlook. Renewable and Sustainable Energy Reviews. 2015;44:149-58.

[38] International Standard 14040. Environmental management - life cycle assessment - principles and framework. Geneva: International Organization for Standardization (ISO); 2006.

[39] Sharma A, Saxena A, Sethi M, Shree V, Varun. Life cycle assessment of buildings: A review. Renewable and Sustainable Energy Reviews. 2011;15:871-5.

[40] Chau CK, Leung TM, Ng WY. A review on Life Cycle Assessment, Life Cycle Energy Assessment and Life Cycle Carbon Emissions Assessment on buildings. Appl Energ. 2015;143:395-413.

[41] Chastas P, Theodosiou T, Bikas D. Embodied energy in residential buildings-towards the nearly zero energy building: A literature review. Building and Environment.

[42] Lotteau M, Loubet P, Pousse M, Dufrasnes E, Sonnemann G. Critical review of life cycle assessment (LCA) for the built environment at the neighborhood scale. Building and Environment. 2015;93, Part 2:165-78.

[43] Nichols BG, Kockelman KM. Life-cycle energy implications of different residential settings: Recognizing buildings, travel, and public infrastructure. Energy Policy. 2014;68:232-42.

[44] Stephan A, Crawford RH, de Myttenaere K. Multi-scale life cycle energy analysis of a lowdensity suburban neighbourhood in Melbourne, Australia. Building and Environment. 2013;68:3549.
[45] Pincetl S, Chester M, Circella G, Fraser A, Mini $C$, Murphy $S$, et al. Enabling Future Sustainability Transitions. J Ind Ecol. 2014;18:871-82.

[46] Zhu X. GIS and Urban Mining. Resources. 2014;3:235-47.

[47] Swan LG, Ugursal VI. Modeling of end-use energy consumption in the residential sector: $\mathrm{A}$ review of modeling techniques. Renewable and Sustainable Energy Reviews. 2009;13:1819-35.

[48] Stephan A. Towards a comprehensive energy assessment of residential buildings. A multi-scale life cycle energy analysis framework [Ph.D. thesis]. Brussels: Université Libre de Bruxelles and The University of Melbourne; 2013.

[49] Stephan A, Crawford RH. A multi-scale lifecycle energy and greenhouse-gas emissions analysis model for residential buildings. Archit Sci Rev. 2014;57:39-48.

[50] Kleemann F, Lederer J, Rechberger $\mathrm{H}$, Fellner J. GIS - based Analysis of Vienna's Material Stock in Buildings. J Ind Ecol. 2016.

[51] Kleemann F, Lederer J, Aschenbrenner P, Rechberger $\mathrm{H}$, Fellner J. A method for determining buildings' material composition prior to demolition. Build Res Inf. 2016;44:51-62.

[52] Assefa G, Ambler C. To demolish or not to demolish: Life cycle consideration of repurposing buildings. Sustainable Cities and Society. 2017;28:146-53.

[53] The Open Data Institute. About. The Open Data Institute, Available from https://theodi.org/about, 2016 (Accessed 17/06 2016).

[54] Hammond G, Jones C. Inventory of carbon \& energy: ICE: Sustainable Energy Research Team, Department of Mechanical Engineering, University of Bath Bath, UK; 2008.

[55] Frischknecht $\mathrm{R}$, Jungbluth $\mathrm{N}$, Althaus $\mathrm{H}-\mathrm{J}$, Doka $G$, Dones $R$, Heck $T$, et al. The ecoinvent Database: Overview and Methodological Framework. The International Journal of Life Cycle Assessment. 2005;10:3-9.

[56] Treloar GJ, Crawford RH. Database of embodied energy and water values for materials. Melbourne: The University of Melbourne; 2010.

[57] Fay R. Comparative life cycle energy studies of typical Australian suburban dwellings. Australia: University of Melbourne; 1999.

[58] Du Bellay J-C, Gauzin-Mueller D, Hoyet R, Zacek M. Neufert. Paris: Dunod; 2006. 
[59] Suh S, Lenzen M, Treloar GJ, Hondo $H$, Horvath A, Huppes G, et al. System boundary selection in life-cycle inventories using hybrid approaches. Environ Sci Technol. 2004;38:657-64. [60] Treloar GJ. A comprehensive embodied energy analysis framework [Ph.D. Thesis]. Geelong: Deakin University; 1998.

[61] Lenzen M, Treloar GJ. Endogenising capital: a comparison of two methods. Journal of Applied Input-Output Analysis. 2004;10:10.

[62] Rauf A, Crawford RH. Building service life and its effect on the life cycle embodied energy of buildings. Energy. 2015;79:140-8.

[63] Hashimoto S, Tanikawa H, Moriguchi Y. Framework for estimating potential wastes and secondary resources accumulated within an economy - A case study of construction minerals in Japan. Waste Management. 2009;29:2859-66.

[64] Goldstein BP, Herbøl M, Figueroa MJ. Gaps in tools assessing the energy implications of renovation versus rebuilding decisions. Current Opinion in Environmental Sustainability. 2013;5:244-50.

[65] Weisz H, Steinberger JK. Reducing energy and material flows in cities. Current Opinion in Environmental Sustainability. 2010;2:185-92.

[66] ABS. Census of population. Australian Bureau of Statistics, Available from http://www.abs.gov.au/websitedbs/censushome. nsf/home/census?opendocument\&navpos=10,

2011 (Accessed September 29 2014).

[67] BITRE. Population growth, jobs growth and commuting flows in Melbourne. Melbourne, Report 125. Canberra ACT: Bureau of Infrastructure, Transport and Regional Economics; 2011. p.404.

[68] City of Melbourne. Census of Land Use and Employment. 2015 ed. Melbourne 2015.

[69] City of Melbourne. Open Data. City of Melbourne, Available from

http://www.melbourne.vic.gov.au/aboutcouncil/governance-transparency/Pages/Opendata.aspx, 2016 (Accessed 22/06 2016).

[70] Fuller R, Crawford RH. Impact of past and future residential housing development patterns on energy demand and related emissions. Journal of Housing and the Built Environment. 2011;26:165-83.

[71] Seo S, Foliente G, Lipkin F, Yum K-K, Anticev J, Egan $S$, et al. Inner Melbourne Energy
Consumption 2011-2026: Baseline and future scenarios forecasts for the residential and commercial sectors. Melbourne: CSIRO; 2014.

[72] Stephan A, Athanassiadis A. Properties of the 48 building archetypes used to characterise the building stock of the City of Melbourne, Australia. Figshare, Available from https://dx.doi.org/10.6084/m9.figshare.3464099.v 2, 27/06/2016, 2016 (Accessed 10/08 2016).

[73] Stephan A, Athanassiadis A. Construction assemblies used in 48 building archetypes representing the current building stock of the City of Melbourne, Australia. Figshare, Available from https://dx.doi.org/10.6084/m9.figshare.3464096, 27/06/2016, 2016 (Accessed 10/08 2016).

[74] Richardson JN, Coelho RF, Adriaenssens S. A unified stochastic framework for robust topology optimization of continuum and truss-like structures. Engineering Optimization. 2016;48:334-50.

[75] Valipour M. Optimization of neural networks for precipitation analysis in a humid region to detect drought and wet year alarms. Meteorological Applications. 2016;23:91-100.

[76] Powell MJD. A Direct Search Optimization Method That Models the Objective and Constraint Functions by Linear Interpolation. In: Gomez S, Hennart J-P, editors. Advances in Optimization and Numerical Analysis. Dordrecht: Springer Netherlands; 1994. p. 51-67.

[77] Powell MJD. Direct search algorithms for optimization calculations. Acta Numerica. 1998;7:287-336.

[78] Powell MJD. A view of algorithms for optimization without derivatives. Cambridge University Technical Report. Cambridge: Cambridge University; 2007.

[79] Treloar GJ, McCoubrie A, Love PED, lyerRaniga U. Embodied energy analysis of fixtures, fittings and furniture in office buildings. Facilities. 1999;17:403-9.

[80] Crawford RH. Post-occupancy life cycle energy assessment of a residential building in Australia. Archit Sci Rev. 2013;57:1 14-24.

[81] Pesonen H, Ekvall T, Fleischer G, Huppes G, Jahn C, Klos Z, et al. Framework for scenario development in LCA. The International Journal of Life Cycle Assessment. 2000;5:21-30.

[82] Wallsten B, Magnusson D, Andersson S, Krook J. The economic conditions for urban 
This is the accepted version of the manuscript accepted in Building and Environment. For the full paper please go to : http://dx.doi.org/10.1016/j.buildenv.2016.11.043 or lookup the paper on Google Scholar

infrastructure mining: Using GIS to prospect hibernating copper stocks. Resources, Conservation and Recycling. 2015;103:85-97.

[83] Wu H, Wang J, Duan H, Ouyang L, Huang W, Zuo J. An innovative approach to managing demolition waste via GIS (geographic information system): a case study in Shenzhen city, China. J Clean Prod. 2016;112, Part 1:494-503.

[84] Realff MJ, Ammons JC, Newton DJ. Robust reverse production system design for carpet recycling. IIE Transactions. 2004;36:767-76.

[85] Yamasue E, Minamino R, Tanikawa H, Daigo I, Okumura $\mathrm{H}$, Ishihara $\mathrm{KN}$, et al. Quality Evaluation of Steel, Aluminum, and Road Material Recycled from End-of-Life Urban Buildings in Japan in Terms of Total Material Requirement. J Ind Ecol. 2013;17:555-65.

[86] Le Moigne J-L. La modélisation des systèmes complexes. [Nouv. éd.] ed. Paris: Dunod; 1999. 


\section{University Library}

\section{- M M I N E R VA A gateway to Melbourne's research publications}

Minerva Access is the Institutional Repository of The University of Melbourne

Author/s:

Stephan, A;Athanassiadis, A

Title:

Quantifying and mapping embodied environmental requirements of urban building stocks

Date:

2017-03

Citation:

Stephan, A. \& Athanassiadis, A. (2017). Quantifying and mapping embodied environmental requirements of urban building stocks. Building and Environment, 114, pp.187-202. https:// doi.org/10.1016/j.buildenv.2016.11.043.

Persistent Link:

http://hdl.handle.net/11343/123177

License:

Publisher's own licence 